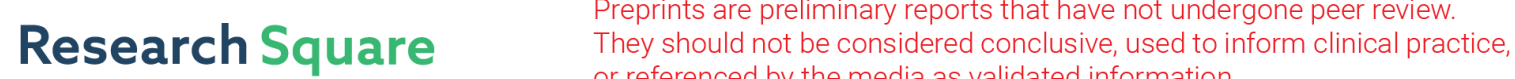 \\ or referenced by the media as validated information. \\ Heat Transfer Analysis of Pin-fin Profiles for Aerospace Application using CFD
}

Manikanda Prabu N ( $\nabla$ mkp.thetrinity@gmail.com )

Presidency University https://orcid.org/0000-0001-6446-9391

\section{Venkateshwaran $\mathbf{P}$}

Muthayammal Engineering College

\section{Ganesh Murali}

Karpagam Academy of Higher Education: Karpagam University

\section{Original Article}

Keywords: Radiating fins, Vacuum chamber, Heat transfer, CFD, Comparison

Posted Date: May 4th, 2021

DOI: https://doi.org/10.21203/rs.3.rs-444406/v1

License: (1) This work is licensed under a Creative Commons Attribution 4.0 International License. Read Full License 


\title{
Heat transfer analysis of pin-fin profiles for aerospace application using
} CFD

\author{
N Manikanda Prabu ${ }^{1 *}$, Venkateshwaran $\mathrm{P}^{2}$, Ganesh Murali $\mathrm{J}^{3}$ \\ ${ }^{1}$ Assistant Professor, School of engineering, Presidency University, Bengaluru, India \\ ${ }^{2}$ Assistant Professor, Mechanical engineering, Muthayammal Engineering College, Namakkal, India. \\ ${ }^{3}$ Professor, Mechanical engineering, Karpagam college of Engineering, Coimbatore, India. \\ *mkp.thetrinity@gmail.com, venkipsamy@gmail.com, ganeshmurali_973@yahoo.in
}

\begin{abstract}
Heat transfer is key phenomena of any cooling systems for the safe and satisfactory operating condition of an appliance. Fins are occupying a greater role in cooling of vehicle systems and specifically, radiating fins are used in space vehicles which represents an important part of the satellite thermal control system. The present work assumed three different pin-fin profiles such as rectangular, stepped and elliptical in space ambiance. The experiment is conducted inside a vacuum chamber setup to show the possibilities of heat transfer enhancement in radiating fins by taking those different profiles, also with Computational fluid dynamics. The performance of fins can be depicted in terms of the thermal conductivity and amount of heat transfer which is possible to evaluate from fin's temperature distribution. However, a temperature dependent thermal conductivity is considered when there is a large temperature difference. Here, the finite volume method is employed to simulate the temperature distribution due to the lower temperature gradient. The results of experimental and numerical analysis are used to compare the fin profiles for suitability in space vehicles.
\end{abstract}

Keywords: Radiating fins, Vacuum chamber, Heat transfer, CFD, Comparison

\section{Introduction}

Heat transfer through convection between a surface and the fluid surrounding can be improved by attaching to the surface thin metallic strips called Fins. In many engineering applications large quantities of heat need to be dissipated from small area which is done by increasing the effective area of the surface. The fin is generally used when the convection heat transfer coefficient is low, especially under free convection. The heat transfer characteristics of fins are highly essential in space appliances in presence of radiation. The profile of the fins needs to be considered in different rate of heat transfer. The optimal dimensions of convective rectangular fins and radial fins with a step change in crosssectional area are experimentally discussed [1-2]. The mechanism of heat transfer in a space radiator or a fin array is conduction combined with radiation in a non-participating medium, and the heat transfer characteristics of simple and radiating fins have been experimentally studied [3-4]. It is reported that [5] optimizing the design of heat pipe or fin type space radiators for the case of uniformly tapered fins as well as for flat fins. The heat pipe or fin space radiators having flat fins with temperature-dependent thermal conductivity have been analyzed [6]. The effect of modification of surface geometry for a radiating pin fins with a test set up of vacuum of $680 \mathrm{~mm} \mathrm{Hg}$ to reduce the contribution of convective heat transfer for a given base temperature and suggested an optimum depth of groove for heat loss to be maximum to the optimum depth of cut the grooved fin and recorded a loss of 1.34 times greater heat per unit mass compared to flat radiating pin fin [7]. The heat transfer rate always vary with the surface area of the fin. Radial or annular fins are discussed and analyzed the heat transfer rate and efficiency of circular and elliptical annular fins for different environmental conditions, which concluded that Elliptical fin efficiency, is more than circular fin [8]. A work studied the thermal performances of a heat sink by varying width design with an impingement cooling. The coupling of the pressure and velocity in terms of momentum energy equations are performed through SIMPLEC algorithm [9]. It is reported that the possibilities of heat transfer from different cross sectional area of rectangular fins and optimized for greater heat transfer rate [10]. The effect of heat transfer and effectiveness of rectangular, trapezoidal and concave parabolic profiles are investigated and comparative statement done [11]. Similarly it is experimentally analyzed for stepped fins and annular elliptical fins with internal heat generation which 
includes the effect of heat generation on fin efficiency $[12,13]$.The heat transfer and friction characteristic using dimple based on the principle of the scrubbing, cooling of action fluid taking place inside the dimple were discussed $[14,15]$. Natural convection heat transfer from the horizontal stepped threaded pin fin arrays, the geometrical parameters are investigated and the effect by fin spacing, length of fin, height of pin and the temperature difference between fins and surrounding, by the horizontal fin arrays the heat is transfer [16]. Experimental analysis of a heat transfer enhancement and cylindrical cross section area perforated pin fins in a rectangular channel is carried out. Solid cylindrical pin fins leads to heat transfer increasing the cylindrical pin fins and increase the efficiency varies depend upon the material and there clearance ratio and enter fin [17]. To predict the thermal performance of triangular fins (array) within an enclosure which is vertically oriented and air filled to analyze the effects of several parameters and their wide ranges [18]. An application of modified Bessel functions in the analysis of fin heat transfer with differential equations were formulated from the fundamentals heat transfer modes [19]. It was analyzed that, the heat transfer on a wall containing triangular fins partially embedded in its volume. Combined heat diffusion equations governing each constituent were solved numerically using an iterative finite volume method [20]. It was observed that, the fin-root can act as a heat sink and heat source simultaneously for the wall. The heat transfer rate by combined system was clearly seen to be maximized at a particular fin-root length. The heat transfer rate through the triangular root finned wall is recommended to utilize. Heat transfer characteristics of a natural convection heat flow on a vertical and symmetrical triangular fin arrays were studied [21]. The results were compared with equivalent rectangular profile fin arrays. It is also observed that with increase in Grashoff number, average and local Nusselt number $(\mathrm{Nu})$ gets increased. Similarly average $\mathrm{Nu}$ increases with spacing whereas local $\mathrm{Nu}$ increases to maximum value [22]. The computational analysis of fins with different notches [23], fins shapes [24], and optimization of stepped fin [25] are discussed with various temperature distribution. From the literature survey, fundamental analysis of pin-fin profiles and existing cooling technology for space vehicles are theoretically studied which provided a potential idea to proceed with this work.

\section{Experimental}

Considering the space applications of radiating fins, the experimental setup has been carried out in vacuum chamber as shown in fig 1 . The continuous temperature variation for three different profiles has been monitored and tabulated as shown in table 1, 2, 3.The values are observed by inserting different fins at keeping current as uniform with variation in voltage and temperatures are tabulated. Using these values, the total heat transfer rate of each fins are calculated. Table 1 shows the temperature distribution of rectangular fins at experimental time. Similarly table 2 and 3 shows the temperature distribution of stepped and elliptical profiles.
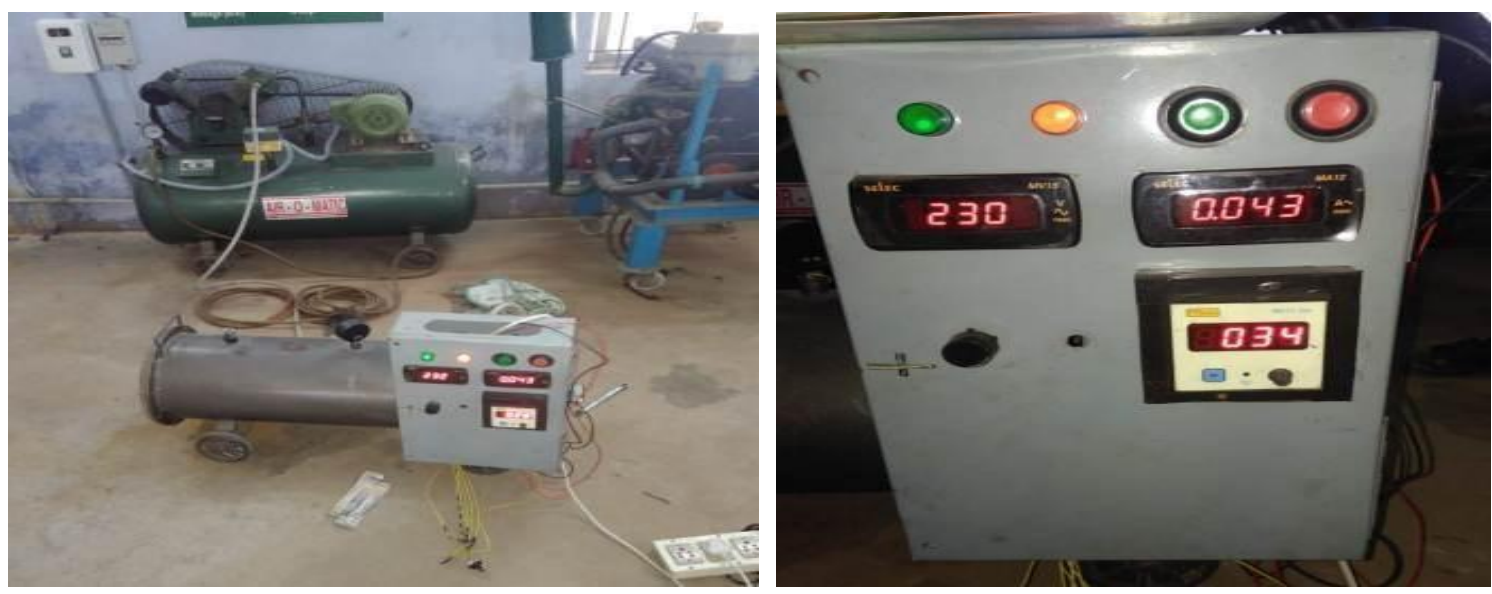

Fig 1: Experimental set up 


\subsection{Temperature distribution}

Temperature distribution is major criteria in heat transfer analysis of a fin. The following assumptions are taken during the theoretical analysis,

- Steady flow heat conduction

- Axial heat conduction is negligible

- No internal heat generation

- Heat transfer co-efficient is constant

- Constant thermal conductivity

Table 1: Temperature distribution of rectangular fin

\begin{tabular}{|c|c|c|c|c|c|c|c|c|c|}
\hline S. No & Amphs & Volts & Time & T1 & T2 & T3 & T4 & T5 & T6 \\
\hline 1 & 0.041 & 225 & 11.40 & 30 & 27 & 23 & 24 & 23 & 23 \\
\hline 2 & 0.040 & 224 & 11.44 & 40 & 34 & 24 & 24 & 23 & 24 \\
\hline 3 & 0.040 & 224 & 11.47 & 50 & 42 & 25 & 25 & 24 & 24 \\
\hline 4 & 0.041 & 226 & 11.51 & 58 & 52 & 26 & 27 & 25 & 25 \\
\hline 5 & 0.040 & 225 & 11.56 & 63 & 58 & 27 & 27 & 25 & 26 \\
\hline 6 & 0.042 & 228 & 12.03 & 69 & 67 & 28 & 28 & 29 & 29 \\
\hline 7 & 0.041 & 225 & 12.17 & 82 & 76 & 31 & 31 & 30 & 32 \\
\hline 8 & 0.043 & 236 & 12.18 & 91 & 90 & 36 & 36 & 36 & 35 \\
\hline
\end{tabular}

Table 2: Temperature distribution of Stepped fin

\begin{tabular}{|c|c|c|c|c|c|c|c|c|c|}
\hline S.No & Amphs & Volt & Time & T1 & T2 & T3 & T4 & T5 & T6 \\
\hline 1 & 0.041 & 225 & 11.34 & 36 & 29 & 26 & 25 & 23 & 23 \\
\hline 2 & 0.040 & 224 & 11.41 & 43 & 34 & 29 & 28 & 28 & 25 \\
\hline 3 & 0.040 & 224 & 11.43 & 49 & 42 & 36 & 33 & 31 & 26 \\
\hline 4 & 0.041 & 226 & 11.47 & 62 & 58 & 41 & 40 & 40 & 27 \\
\hline 5 & 0.040 & 225 & 11.51 & 70 & 61 & 49 & 43 & 39 & 29 \\
\hline 6 & 0.042 & 228 & 12.01 & 78 & 72 & 41 & 37 & 36 & 29 \\
\hline 7 & 0.041 & 225 & 12.09 & 94 & 77 & 45 & 44 & 38 & 31 \\
\hline 8 & 0.043 & 236 & 12.13 & 96 & 86 & 54 & 43 & 41 & 32 \\
\hline
\end{tabular}

Table 3: Temperature distribution of elliptical fin

\begin{tabular}{|c|c|c|c|c|c|c|c|c|c|}
\hline S.No & Amphs & Volt & Time & T1 & T2 & T3 & T4 & T5 & T6 \\
\hline 1 & 0.041 & 225 & 11.30 & 36 & 29 & 26 & 25 & 23 & 23 \\
\hline 2 & 0.040 & 224 & 11.41 & 43 & 34 & 29 & 28 & 28 & 25 \\
\hline 3 & 0.040 & 224 & 11.40 & 49 & 42 & 36 & 33 & 31 & 24 \\
\hline 4 & 0.041 & 226 & 11.43 & 72 & 58 & 41 & 40 & 40 & 26 \\
\hline 5 & 0.040 & 225 & 11.51 & 76 & 61 & 49 & 43 & 39 & 32 \\
\hline 6 & 0.042 & 228 & 12.03 & 83 & 72 & 41 & 37 & 36 & 31 \\
\hline 7 & 0.041 & 225 & 12.07 & 97 & 77 & 45 & 44 & 38 & 33 \\
\hline 8 & 0.043 & 236 & 12.11 & 98 & 86 & 54 & 43 & 41 & 34 \\
\hline
\end{tabular}

\subsection{Modelling and Analysis}


The heat transfer modes in space medium are solely conduction and thermal radiation. The major part in the satellite heat transfer is carried out by thermal radiation. One of the main objectives of a thermal design is to maintain the temperature of a heat dissipating component at or below a specified value. This work is considered to have three different profiles of space radiating fins such as Rectangular, Stepped and elliptical profiles. The modelling is done by Catia software and analysis (solving and post processing step) were performed using ANSYS-Fluent software. Heat transfer rate depends on the variable temperature over surface and the thermodynamic properties of the fluid considered.

Rectangular fin: Rectangular fins are common extended surfaces used in vehicles. The edge of the profile with minimal area leads to maximum possible heat conduction. The heat transfer occurs along the surface of the profile in air flow as shown in fig 2-a. Stepped fin: Stepped fins are the fin profile having a step change in thickness and it is exposed air domain as shown in fig 2-b. Here the problem has been divided into thin and thick sections. The resulting solved two non-linear heat transfer equations with non-linear boundary conditions.

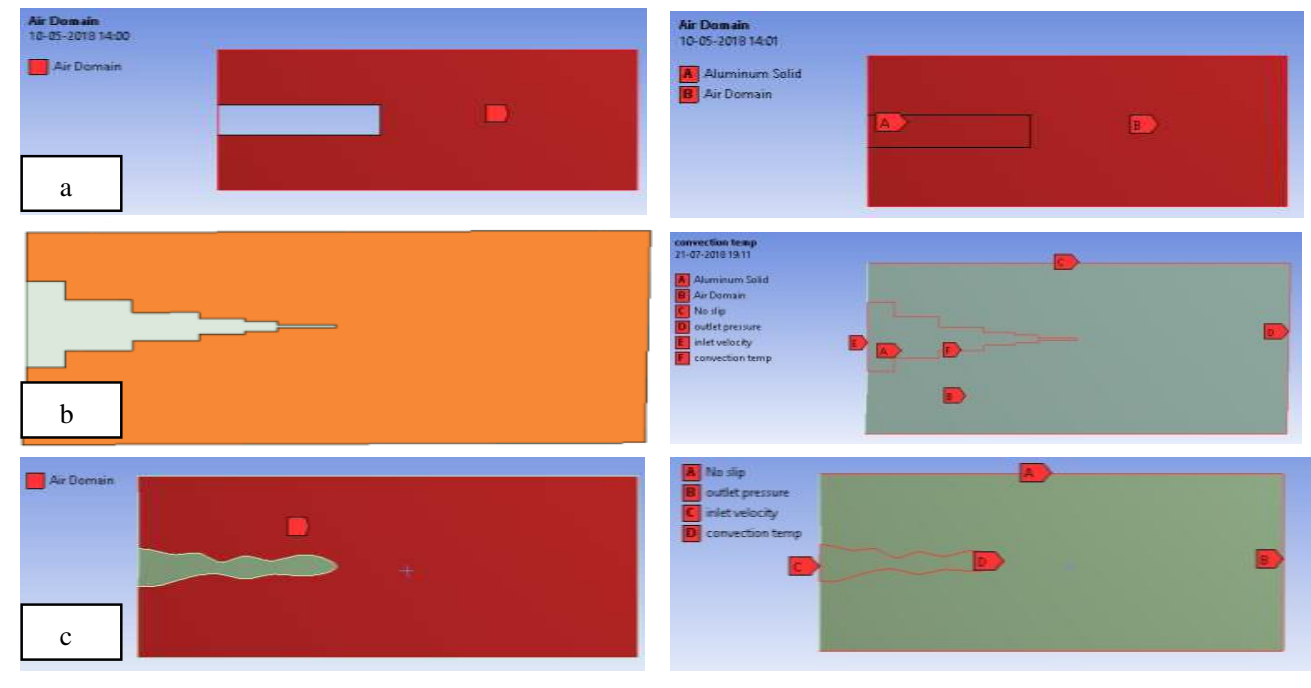

Fig 2: Different Fin profiles

Elliptical fin: This kind of fin has a standard elliptical cross-section in shape with the minor axis length being equal to the diameter of circular fin and the major axis is 1.67 times the minor axis length. The relative air domain of the geometry is given in Figure 2-c. The surface area of SEF (standard elliptical fin) is calculated to be 1.35 times the surface area of the circular fin, but the effective front areas are the same for both fins because, the minor axis of SEF is equal to the circular fin diameter.

\section{Results and discussion}

The experimental and numerical analysis was carried out by assuming one dimensional (1D) heat transfer models of selected fin profiles. Temperature profiles are plotted for different iterations of one dimensional analysis and heat transfer rates were computed and results are discussed with improved stats.

\subsection{Heat transfer $(Q)$}

The efficiency of the fin surfaces can be understood by its rate of heat flow or lost to the atmosphere. It depends on the heat transfer co-efficient and contact area of the fin material used. Here, the material and length has been considered as uniform for three profiles, but the area of cross section may be varied. It depends on the shape of the fin assumed. For the same power supply the variation of heat transfer along the fin is obtained and tabulated in table 4 . In general, heat lost by fin can be expressed by

$$
Q=(h P K A)^{0.5} *(T b-T \infty) * \tanh (m L)
$$

Under these criteria, the calculations were made for the comparison of three profiles which shows the 
possibilities in using elliptical profile with less area when compared to other two profiles.

Table 4: Amount of Heat transfer

\begin{tabular}{|c|c|c|c|c|}
\hline $\begin{array}{c}\text { S. } \\
\text { No }\end{array}$ & Rectangular & Steppe d & Elliptical & Best \\
\hline 1 & 16.0 & 30.2 & 30.3 & Elliptical \\
\hline 2 & 36.6 & 42.0 & 41.9 & Stepped \\
\hline 3 & 59.5 & 53.7 & 58.2 & Rectangular \\
\hline 4 & 75.5 & 81.7 & 107.1 & Elliptical \\
\hline 5 & 84.6 & 95.7 & 102.4 & Elliptical \\
\hline 6 & 91.5 & 114.4 & 121.1 & Elliptical \\
\hline 7 & 114.4 & 147.1 & 149.0 & Elliptical \\
\hline 8 & 128.1 & 149.4 & 149.0 & Stepped \\
\hline
\end{tabular}

Fig 3 shows that, the comparative representation of heat transfer rate of three profiles which results in elliptical profile leads to more Radiative heat transfer.

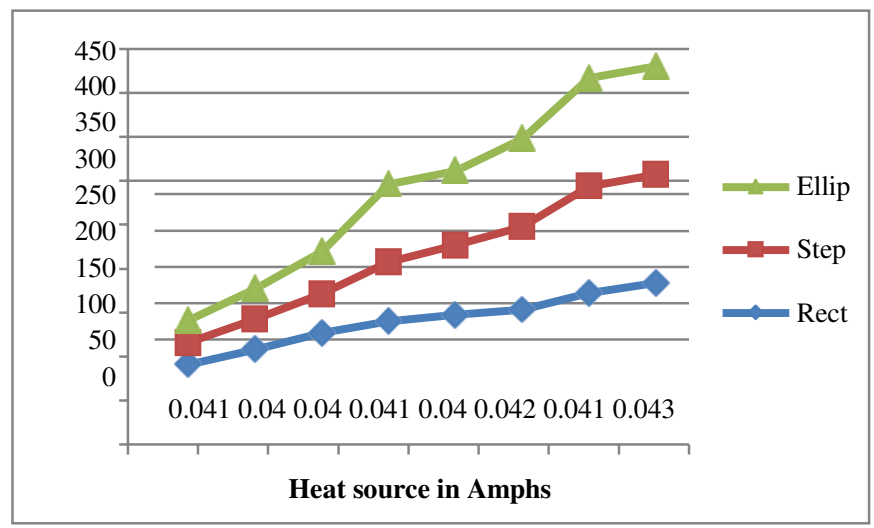

Fig 3: Variation in Heat transfer

\subsection{Temperature distribution}

When the temperature gradient is increased between the fins and the environment, the convection heat transfer co-efficient increased. The amount of heat transfer increased with increasing the surface area of the base object. Sometimes it is not economical or feasible to change the first two options. Thus, adding fins to an object increases the surface area and can sometimes be an economical solution to heat transfer problems. Fin problem analysis consists of two sections such as Thermal conduction through fin's cross section and thermal convection through fin's surface area. For one-dimensional energy balance equation of the fin problem is can be analytically expressed as [25],

$$
\begin{gathered}
\text { A.d/dx }[k \cdot(d T / d x)]-P h(T b-T a)=0 \\
k=k[1+\lambda(T-T a)]
\end{gathered}
$$

The temperature distribution of different profiles of fin is analyzed by Ansys fluent and simulation of each profile is shown in figure for various iterations. The iterations have been accounted on time dependent. Figure 4 indicates the temperature distribution of rectangular fin whereas figure 5 and figure 6 indicates the temperature distribution of stepped fin and elliptical fin respectively. Uniform temperature distribution or thermal gradient will enhance the heat transfer rate gradually. Fig 4, 5, 6 indicates the thermal gradient of three profiles in which stepped and elliptical profile having wide range of temperature distribution. When comparing the theoretical calculations, elliptical fins 
providing uniform distribution of temperature rather than stepped profile.

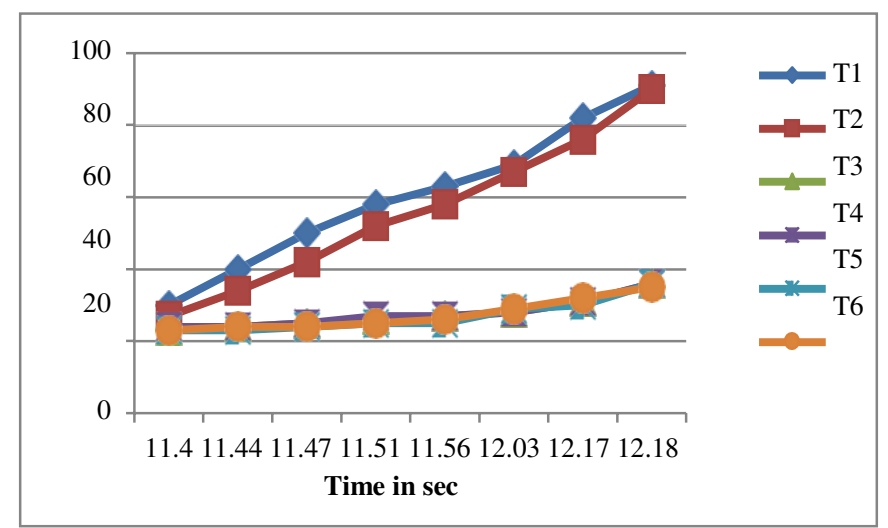

Fig 4: Temperature gradient in Rectangular fin

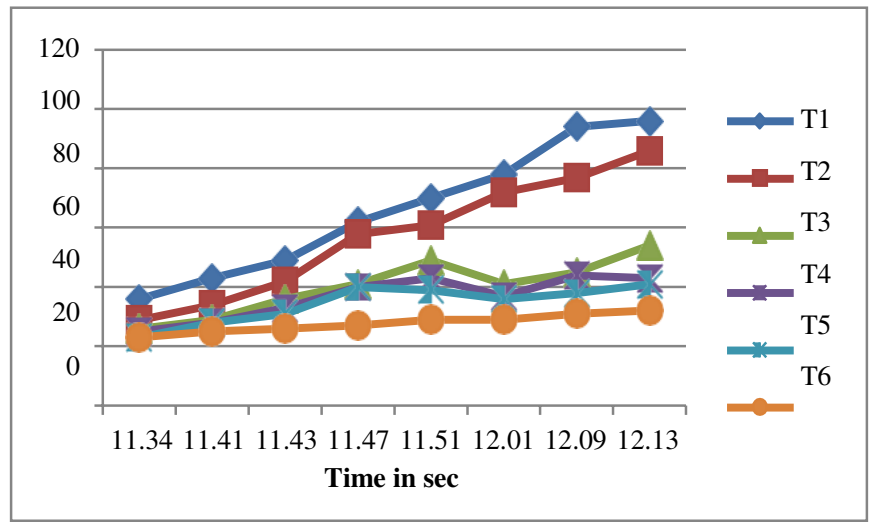

Fig 5: Temperature gradient in Stepped fin

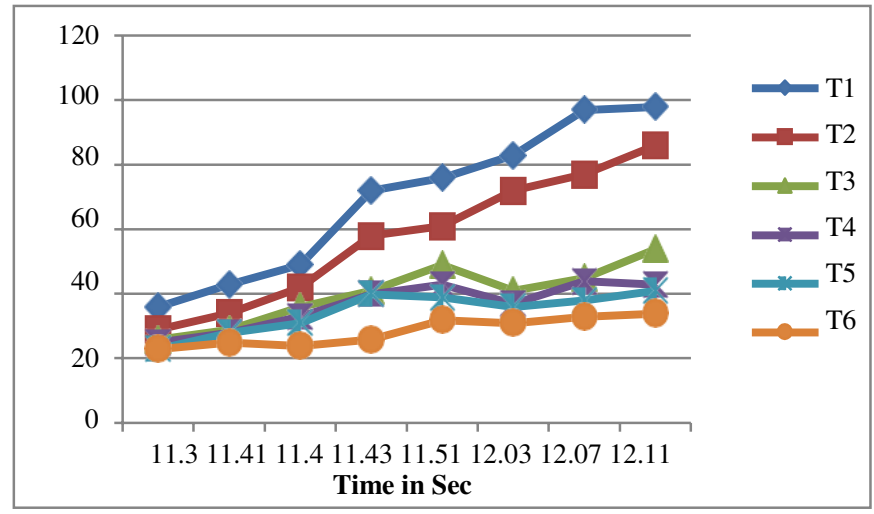

Fig 6: Temperature gradient in Elliptical fin

The simulation in fig 7, 8, 9 clearly shows that the turbulence effect on stepped fin and elliptical fin increases the propagation of temperature compared to rectangular fin. Elliptical profile accelerates the heat radiation compared to other two.

\subsection{Velocity distribution}

The modelled fins are subjected under convective heat transfer also to enumerate the effect of velocity distribution.

The velocity range assumed as $0-3 \mathrm{~m} / \mathrm{s}$ and the pressure between $0-1.01325 \mathrm{bar}$. The direct surface contact of air with rectangular fin surfaces and minimal flow bypass seen when compared to other profiles, hence, no surprise that having less heat transfer co-efficient and effect of air flow is clearly given in Fig. 10. 
The stepped profile has reduced thickness towards air flow direction and it makes more contact surface than rectangular fin, since the heat sink become cooler when compared to Elliptical profile. Obviously it shows enhanced heat transfer co-efficient than rectangular fin and it is shown in fig 11.
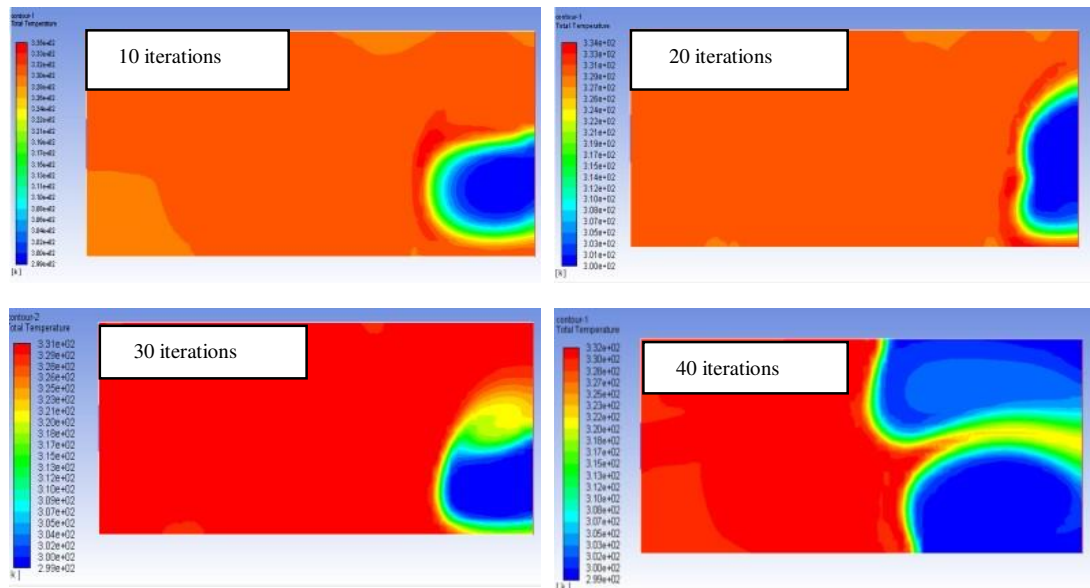

Fig 7: Temperature distribution of Rectangular fin
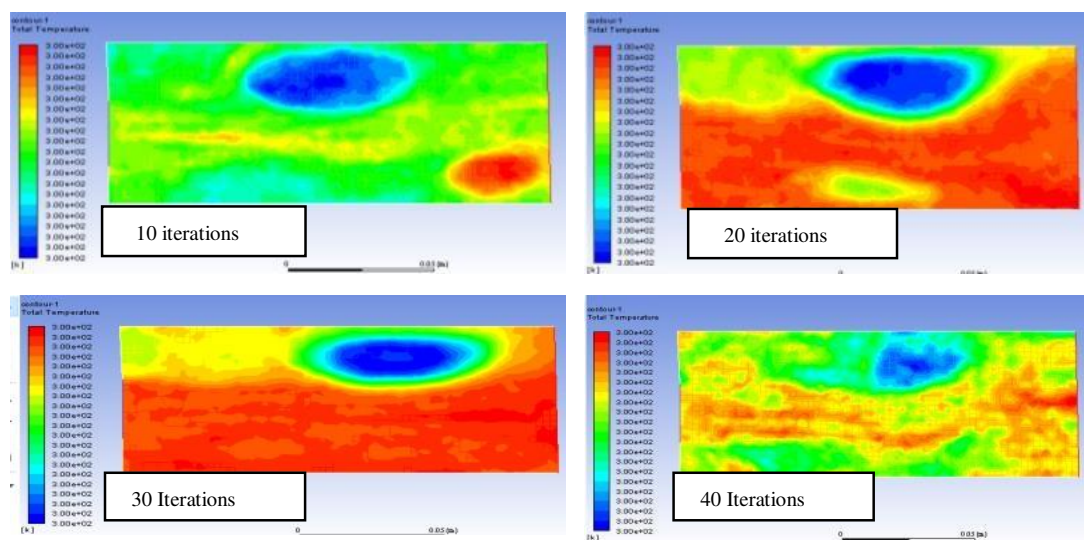

Fig 8: Temperature distribution of Stepped fin

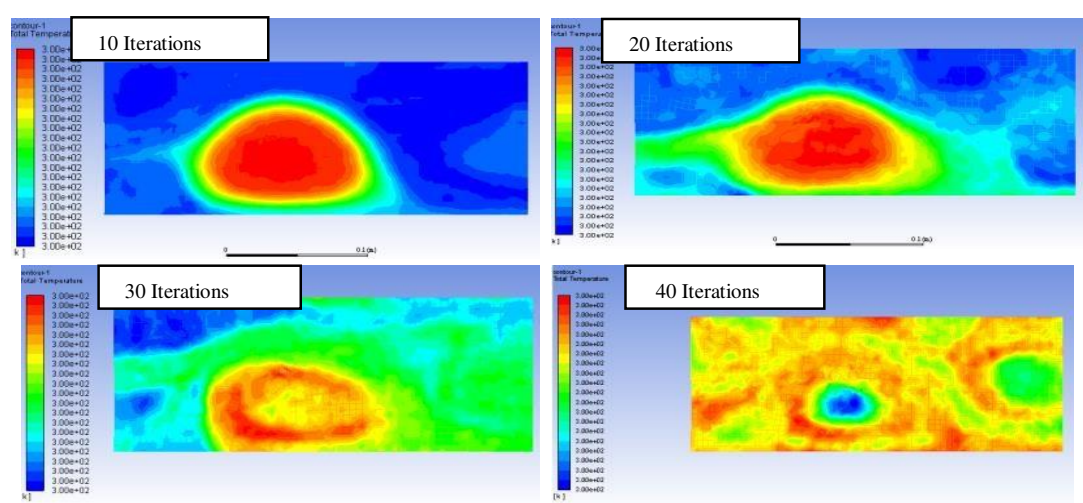

Fig 9: Temperature distribution of elliptical fin

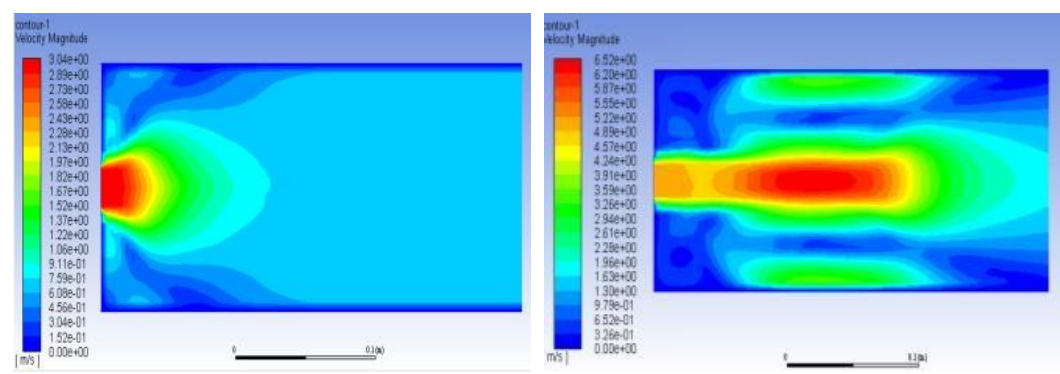


Fig 10: Velocity distribution of Rectangular fin

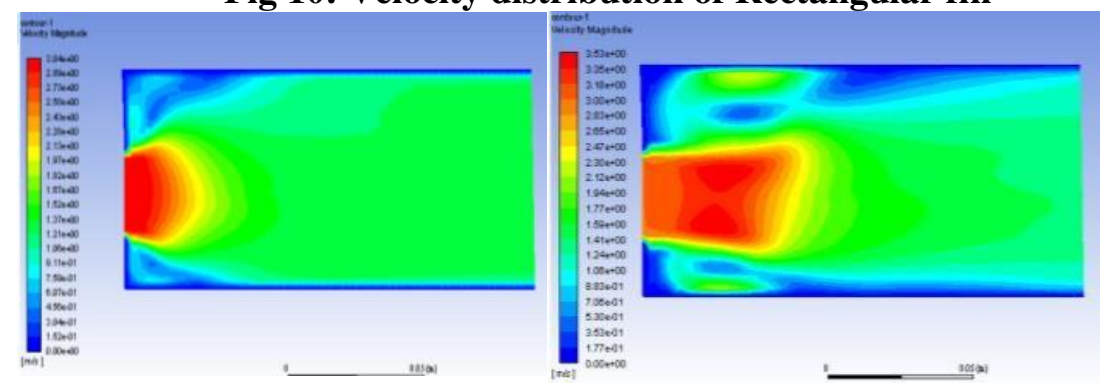

Fig 11: Velocity distribution of stepped fin

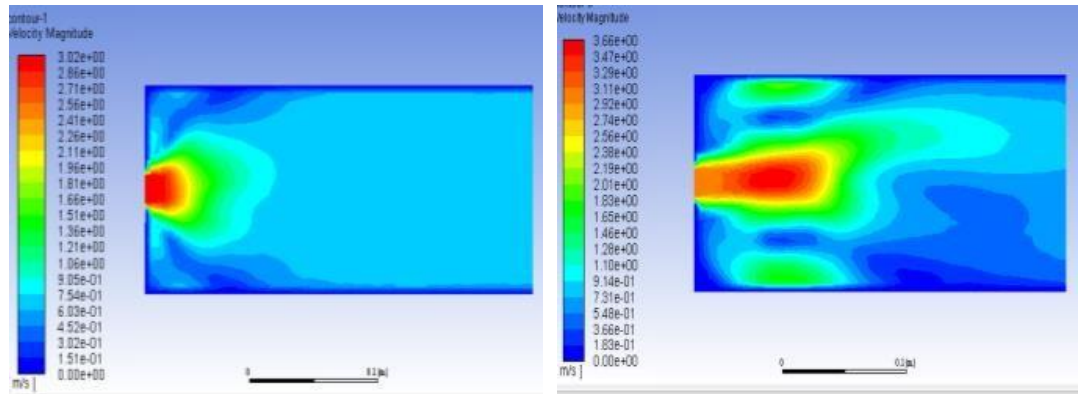

Fig 12: Velocity distribution of elliptical fins

The effect of testing in an elliptical fin at open air flow is shown in Figure 12, where significant flow bypass is seen with the elliptical heat sink. Here, the cross-section of this heat sink represents an obstruction for airflow. Also, the cross-cuts induced more bypass flow than the straight fin, suggesting increased pressure drop and turbulence. This shows that the elliptical airfoil shape has an enhanced heat transfer coefficient which is indirectly related to the air flow velocity.

\section{Conclusion and recommendations}

The present work is experimentally done and identified following suggestions.

- The complete literature summary shows that the parameters and characteristics of heat transfer analysis in different profiles of fins and indicates the possibilities in heat transfer enhancement.

- The temperature distribution along a radiating fin is predicted for different geometric and thermal parameters.

- It is observed that, air flow through the stepped and rectangular fin design is more and also the thermal resistances were approximately equal.

- The elliptic pin fin shows the lowest pressure drops compared to other two. The elliptic pin fin possesses the smallest thermal resistance for the same surface area.

- The rate of heat transfer depends on the contact surface area of the fin.

- The total temperature distribution and heat transfer rate is more than rectangular and stepped fin.

- Hence an elliptical fins could be a good choice when space restriction occurs along one particular direction with the perpendicular direction is relatively unrestricted.

\section{Declaration}

\section{Availability of data and materials}

All data generated during this experimental study are included in this published article. Numerical data will be available on request.

\section{Competing interest}

The authors declare that they have no competing interests.

\section{Funding}


There is no source of external funding. Self-funded project.

\section{Author's contribution}

$\mathrm{N}$ M collected the data for Report writing, calculation and manuscript preparation. P V has carried out the experimental investigation. J G developed a numerical model and analyzed for space atmosphere.

\section{Acknowledgement}

Not applicable

\section{Author's Information}

The corresponding author N Manikanda Prabu is an educator over past 10 years and currently working at Presidency University, Bengaluru, India. He has published 19 international journal and attended many national and international conferences. He is acting as a reviewer in Scopus indexed journals such as Engineering journal (UK), Journal of engineering and technological sciences (Indonesia) and International journal of Nanomanufacturing (Switzerland).

\section{Foot notes}

Not applicable

\section{References}

[1].Aziz, A. (1994). Optimum design of a rectangular fin with a step change in cross-sectional area. International Communications in Heat and Mass Transfer, 21(1), 389-401.

[2].Kundu, B \& Das P. K. (2001). Performance analysis and optimization of annular fin with a step change in thickness. Journal of Heat Transfer, 123, 601-604.

[3].Bartas, J.G. \& Sellers, W.H. (1960). Radiation fin effectiveness. Journal of Heat Transfer, 82(1), 73-75.

[4].Cockfield, R.D. (1968). Structural optimization of a space radiator. Journal of Space craft and Rockets, 1(5), 1240-1241.

[5].Naumann, R. J. (2004). Optimizing the design of space radiators. International Journal of Thermo physics, 25(1), 1929-1941.

[6].Arslanturk, C. (2006). Optimum design of space radiators with temperature-dependent thermal conductivity, Applied Thermal Engineering, 26(1), 1149-1157.

[7].Ganesh murali. J \& Subrahmanya, S. katte. (2008). Experimental investigation of heat transfer enhancement in radiating pin fin, Jordan journal of mechanical and industrial engineering, 2(3), 163-167.

[8].Nagarani, N. (2012). Experimental heat transfer analysis on annular Elliptical fins and Comparison with Circular Fins. European Journal of Scientific Research, 73(2), 143-156.

[9].Yue-Tzu Yang \& Huan-Sen Peng. (2009). Investigation of planted pin fins for heat transfer Enhancement in plate fin heat sink, Microelectronics Reliability, 49,163-169.

[10]. Sharqawy, M.H., Moinuddin. A., \& Zubair S.M. (2012). Heat and mass transfer from annular fins of different cross-sectional area- Temperature distribution and fin efficiency, International Journal of Refrigeration, 35, 365-376.

[11]. Torabi, M., Aziz, A., \& Zhang, K. (2013). A comparative study of longitudinal fins of rectangular, trapezoidal and concave parabolic profiles with multiple nonlinearities, Energy, 51, 243-256.

[12]. Kundu, B \& Kwan soo lee. (2015). Analytical tools for calculating the maximum heat transfer of annular stepped fins with internal heat generation and radiation effects, Energy, 76 (1), 733-748.

[13]. Nemati, H \& Samivand, S. (2015). Performance of annular elliptical fin based on thermo electric geometric parameters, Alexandria engineering journal, 54, 1037-1042.

[14]. Gawai Mathew, V. K., \& Murtuza, S.D. (2013). Experimental investigation of heat transfer by pin fin, International Journal of Engineering and Innovative Technology, 2(7), 202-204.

[15]. Fadi alnaimat \& Mohammed ziauddin. (2021). Experimental investigation of heat transfer in pin-fins heat sinks for cooling applications, Heat and mass transfer, 57, 125-131.

[16]. Baskaya Senol., Sivrioglu Mecit \& Ozek Murat. (2000). Parametric study of natural convection heat transfer from horizontal rectangular fin arrays, International Journal of Thermal Science, 39, 797-805.

[17]. Amul, B dhumne \& Hemant S.Farkade. (2013). Heat transfer analysis of cylindrical performance fin in staggered arrangement, International journal of innovative technology and exploring engineering, 2(1), 225230. 
[18]. Gaurav Kumar., Kamal Raj Sharma., Ankur, D wivedi., Alwar Singh Yadav \& Hariram Patel. (2014). Experimental investigation of Natural convection from heated triangular fin array within a Rectangular array, Research India Publications, 4, 203-210.

[19]. Somunk Teerakulpisut. (1995). Application of Modified Bessel functions in extended surface, Heat Transfer, 22, 61-74.

[20]. Abdul Rahim., Khaled, A \& Abdullatif, A. (2014). Heat transfer enhancement via combined wall and Triangular- Rooted fin system, KSA Journal of Electronics Cooling and Thermal Control, 4, 12-21.

[21]. Narve, N.G., Sane, N.K \& Jadhav, R.T. (2013). Natural Convection Heat Transfer from Symmetrical Triangular Fin Arrays on Vertical Surface, International Journal of Scientific and Engineering Research, 4, 17-23.

[22]. Ganji, D. D \& Dogonchi, A.S. (2014). Analytical investigation of convective heat transfer of a longitudinal fin with temperature-dependent thermal conductivity, heat transfer coefficient and heat generation, International Journal of Physical Science, 9, 466-474.

[23]. Sathishkumar, K. (2017). Computational analysis of heat transfer through fins with different types of notches, International journal of advanced engineering research and science, 4(2), 175-183.

[24]. Pankaj, V Bhaviskar. (2018). To analyze the effect of varying fin shapes for micro cooling, International journal of innovative research in science, engineering and technology, 5(4), 5613-5621.

[25]. Kwang-Yong Kim \& Mi-Ae Moon. (2009). Optimization of a stepped circular pin-fin array to enhance heat transfer performance, Heat mass transfer, 46, 63-74.

[26]. Mokhtarpour, K \& Ganji D.D. (2016). Analysis of temperature distribution through rectangular convective fin using analytical Methods. Innovative Energy \& Research, 5(2), 1-8. 
Figures
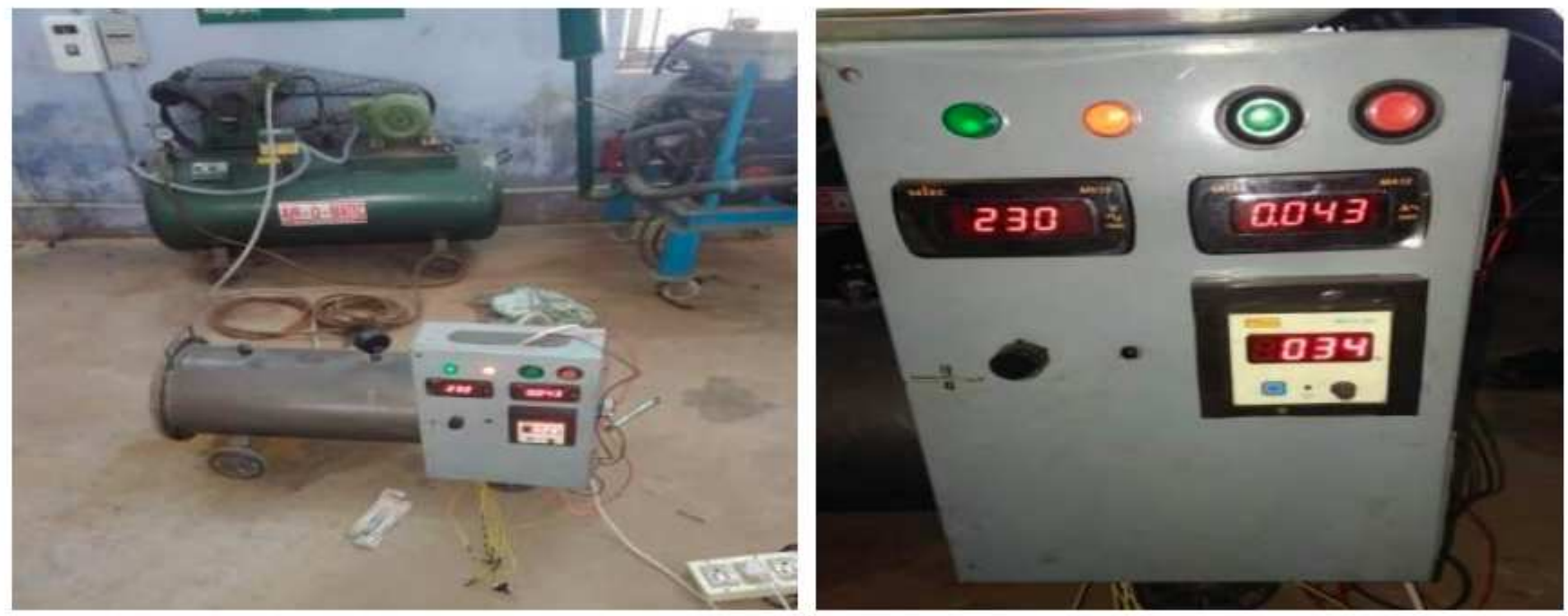

Figure 1

\section{Experimental set up}
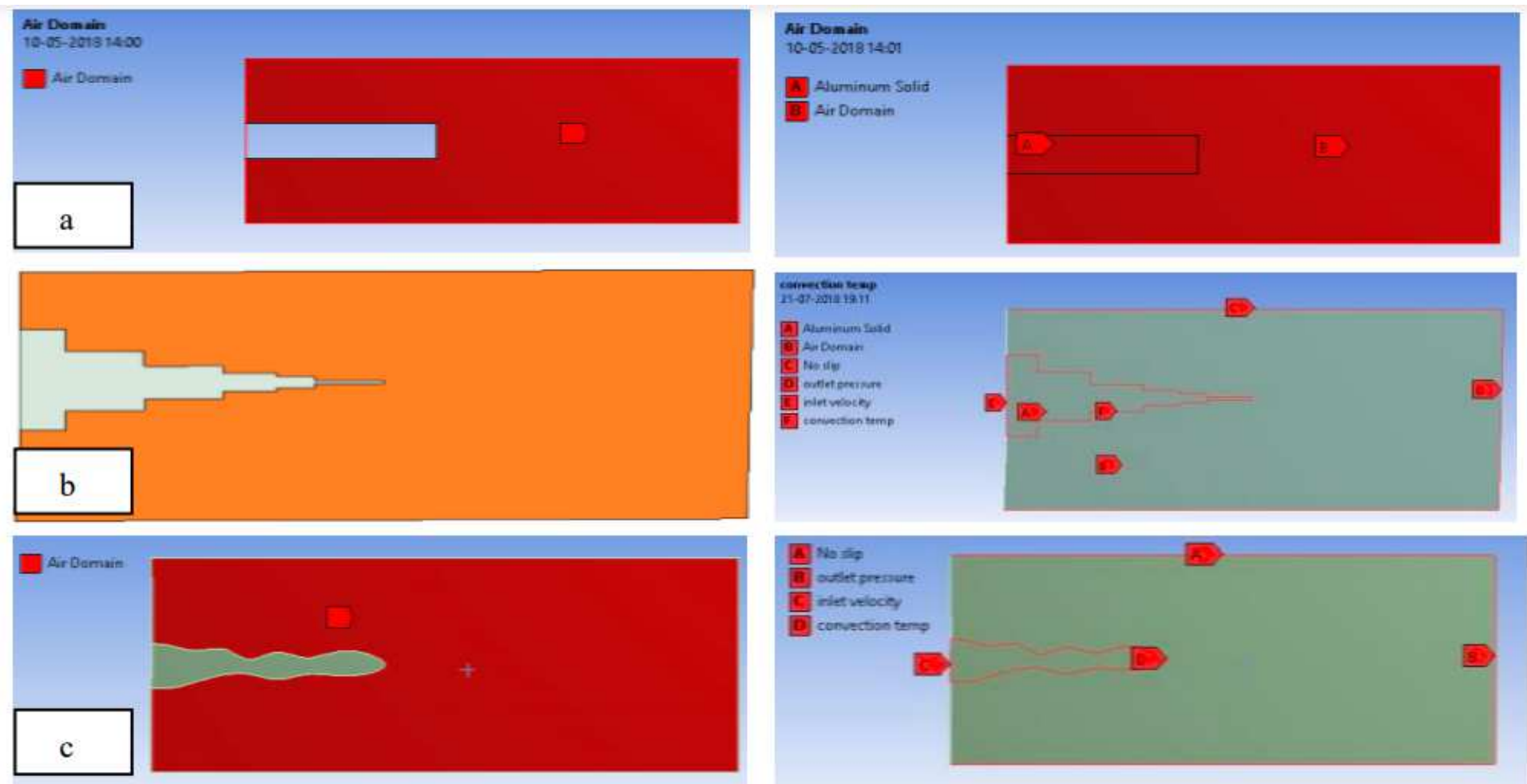

Figure 2

Different Fin profiles 


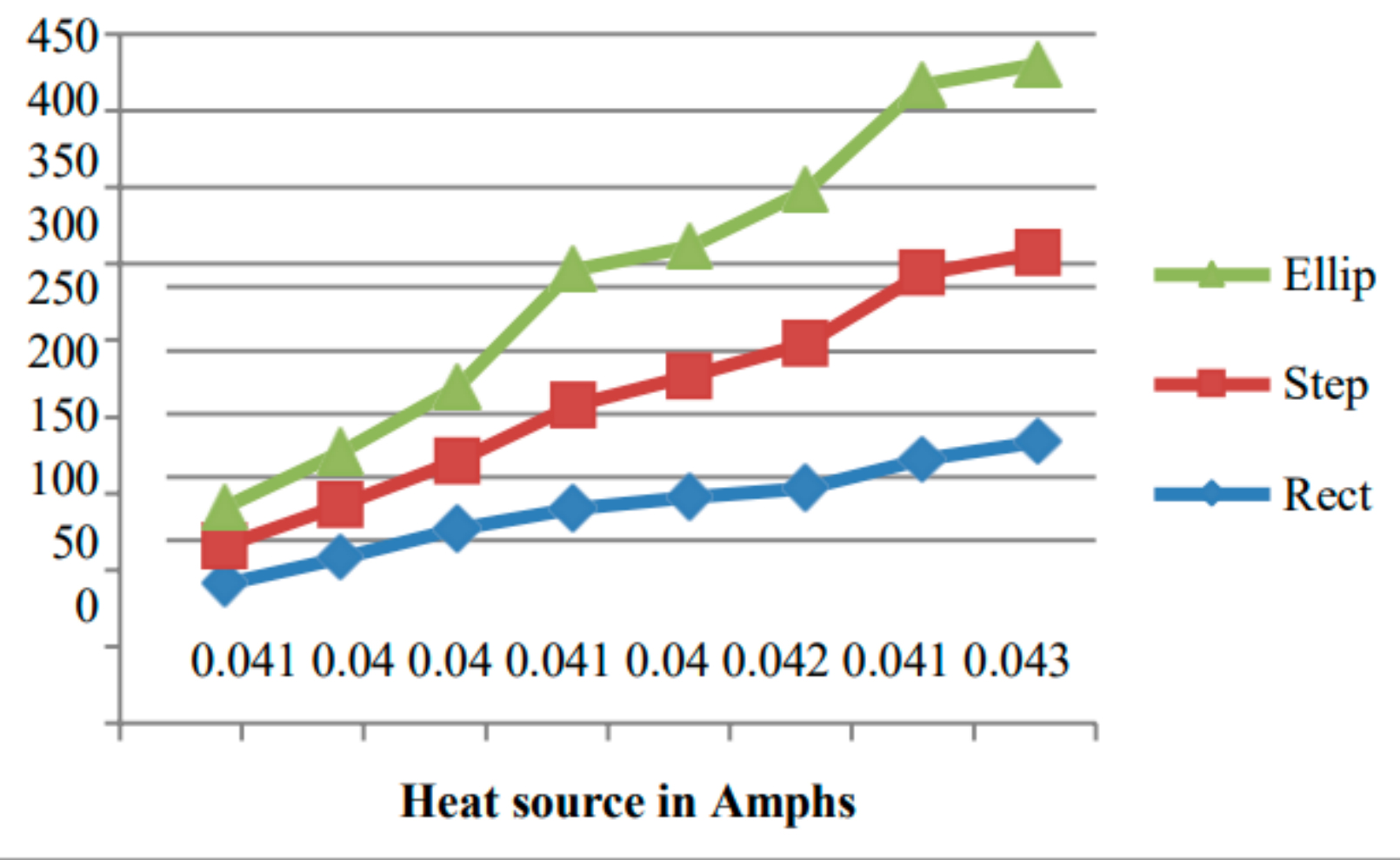

Figure 3

Variation in Heat transfer

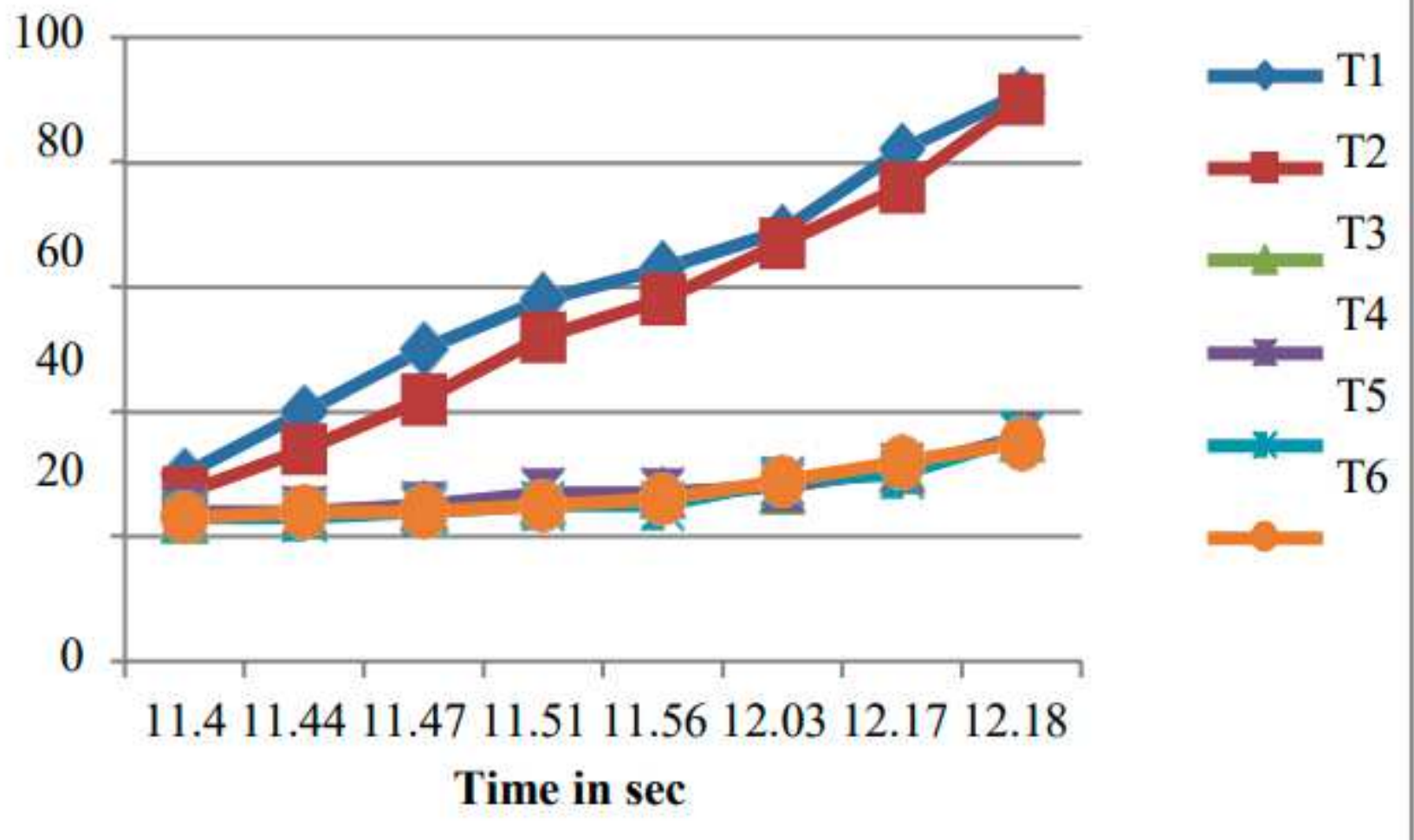

Figure 4 
Temperature gradient in Rectangular fin

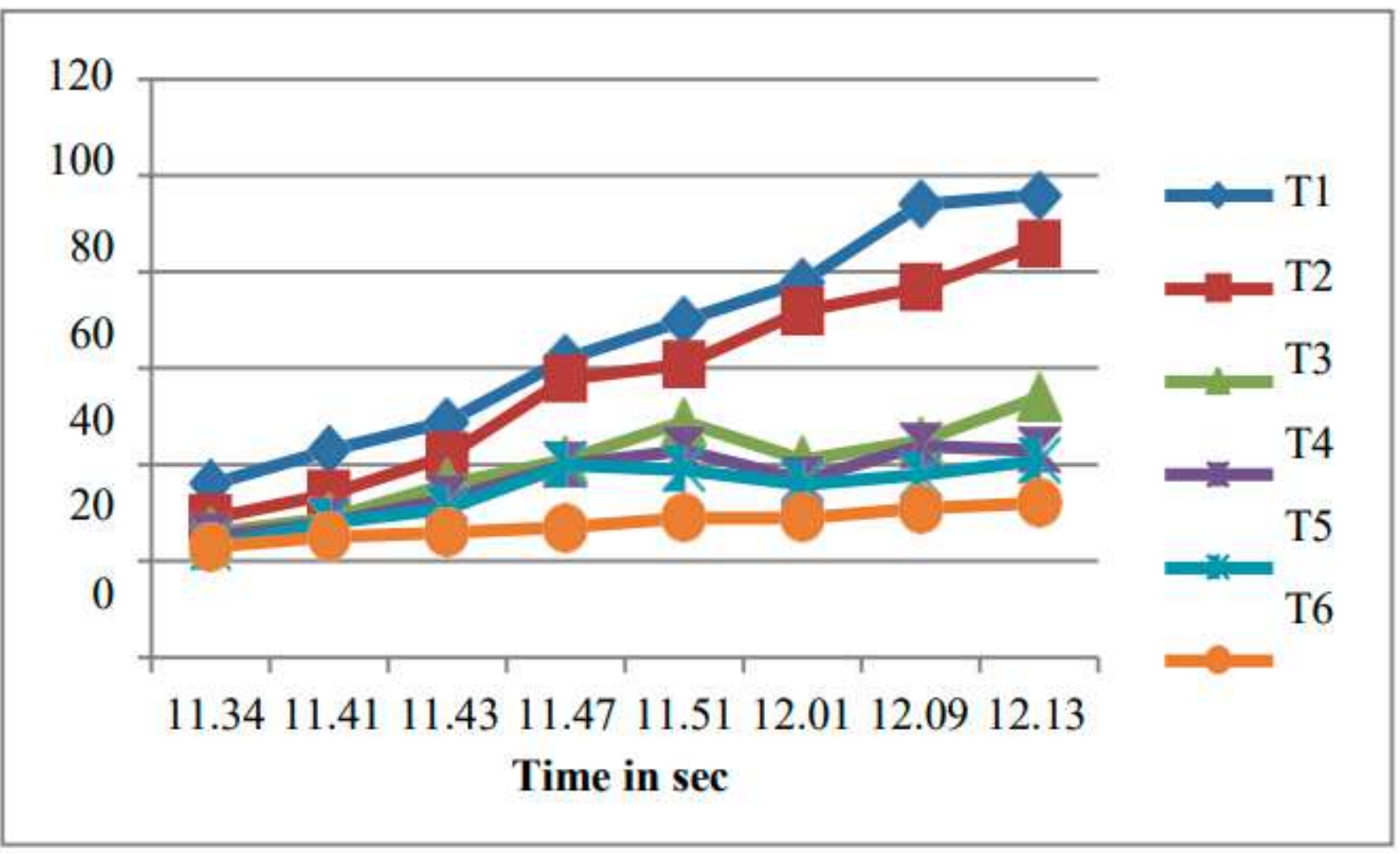

Figure 5

Temperature gradient in Stepped fin

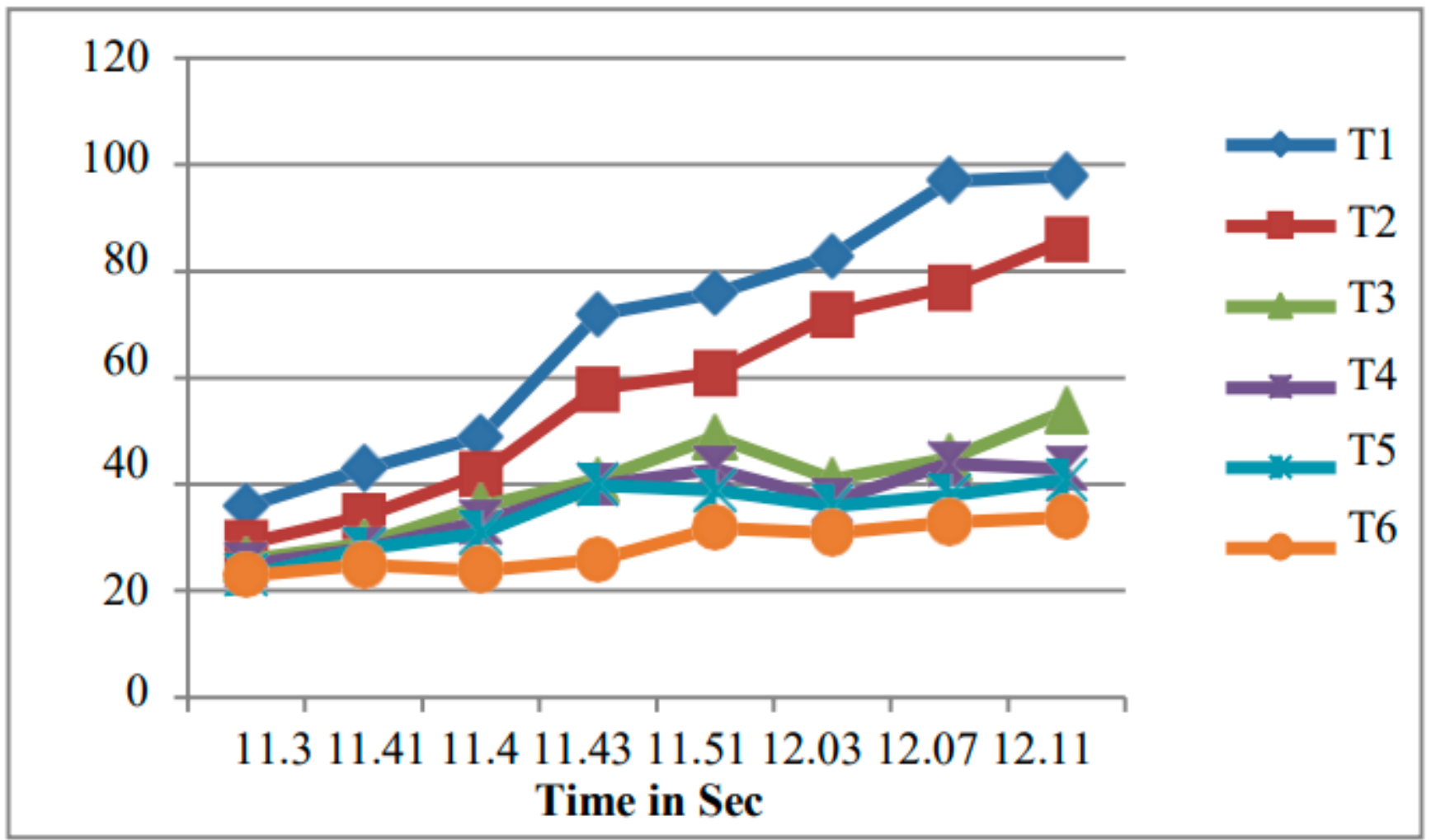


Figure 6

Temperature gradient in Elliptical fin
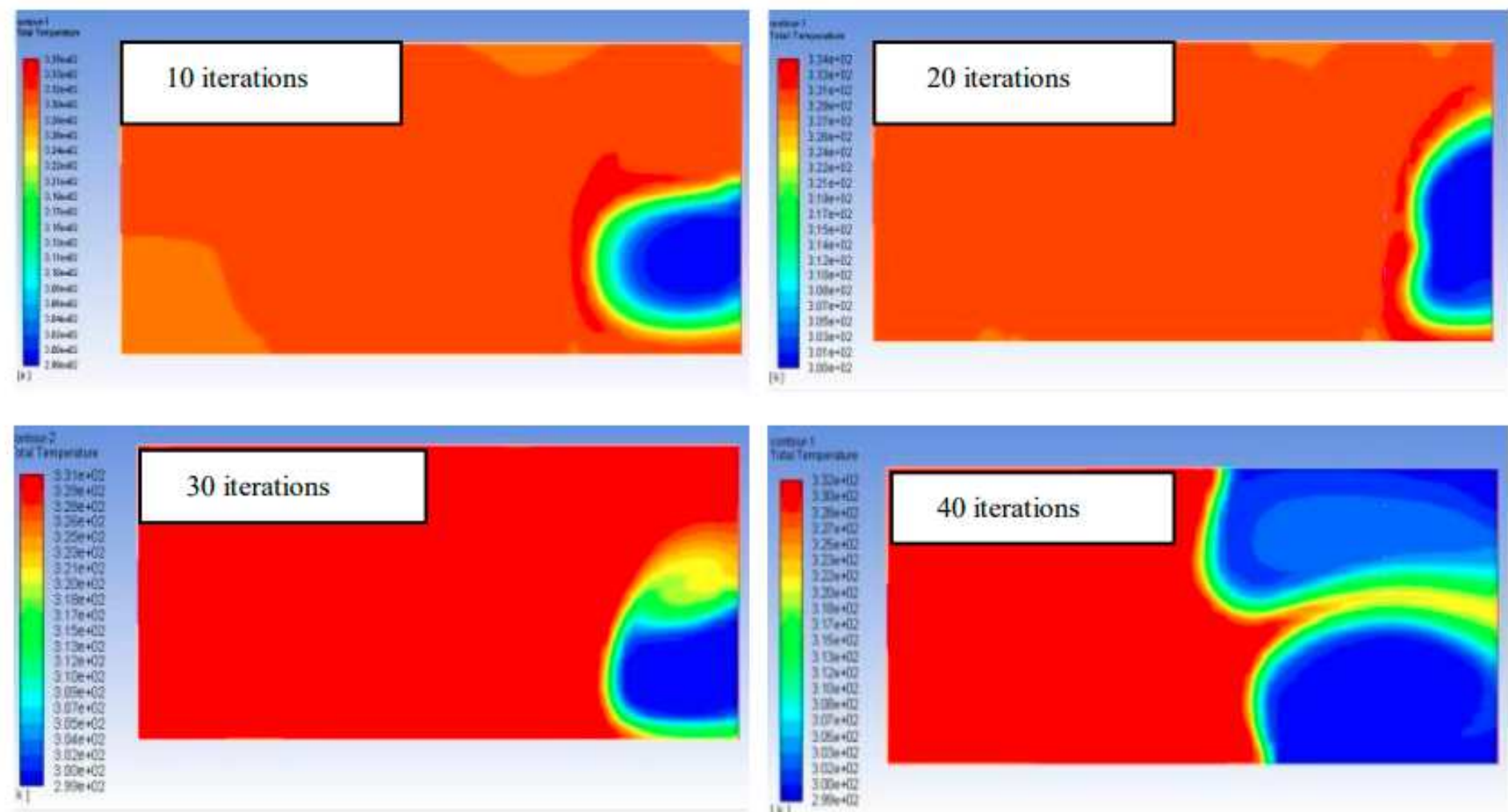

Figure 7

Temperature distribution of Rectangular fin
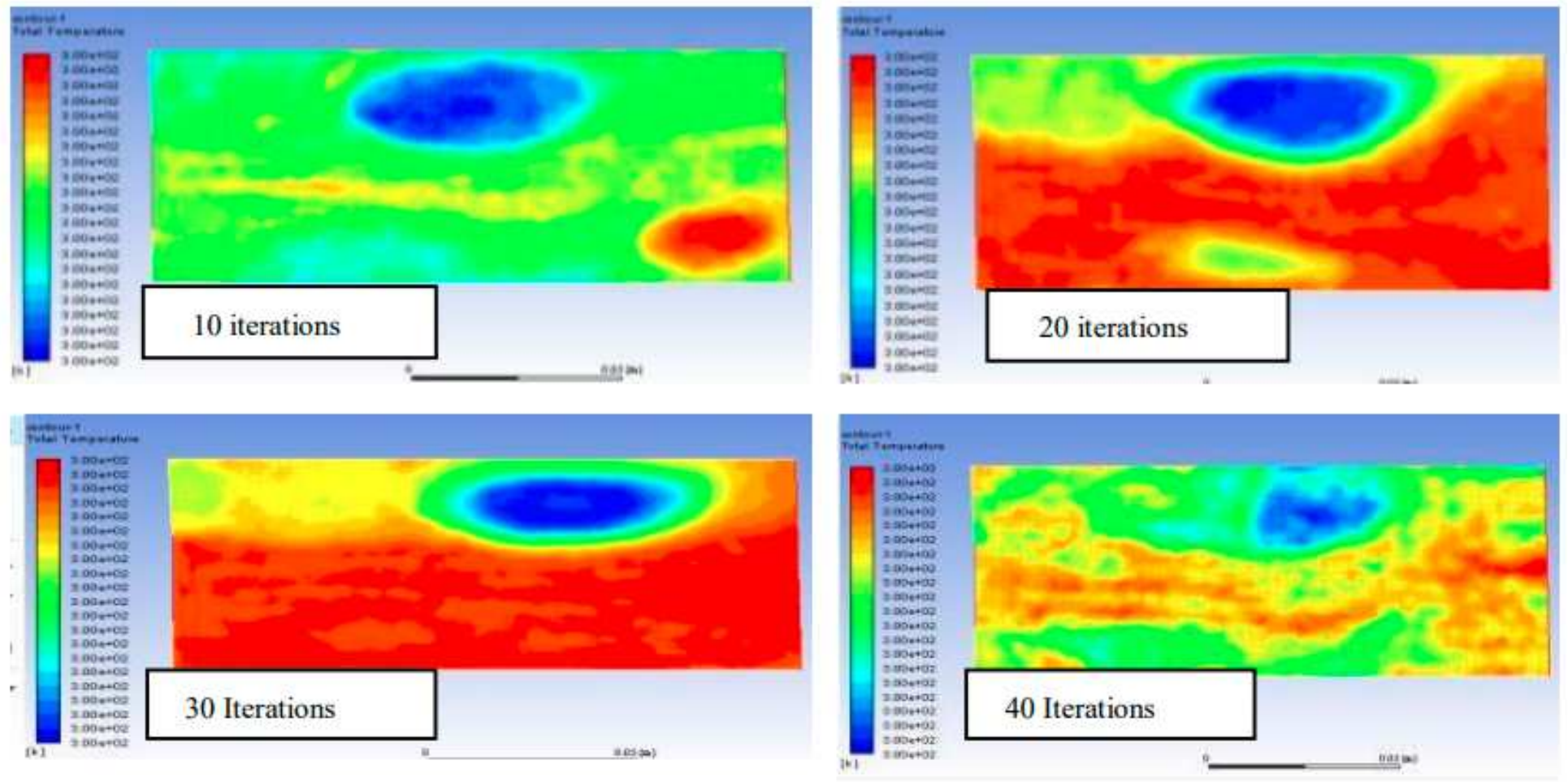
Figure 8

Temperature distribution of Stepped fin

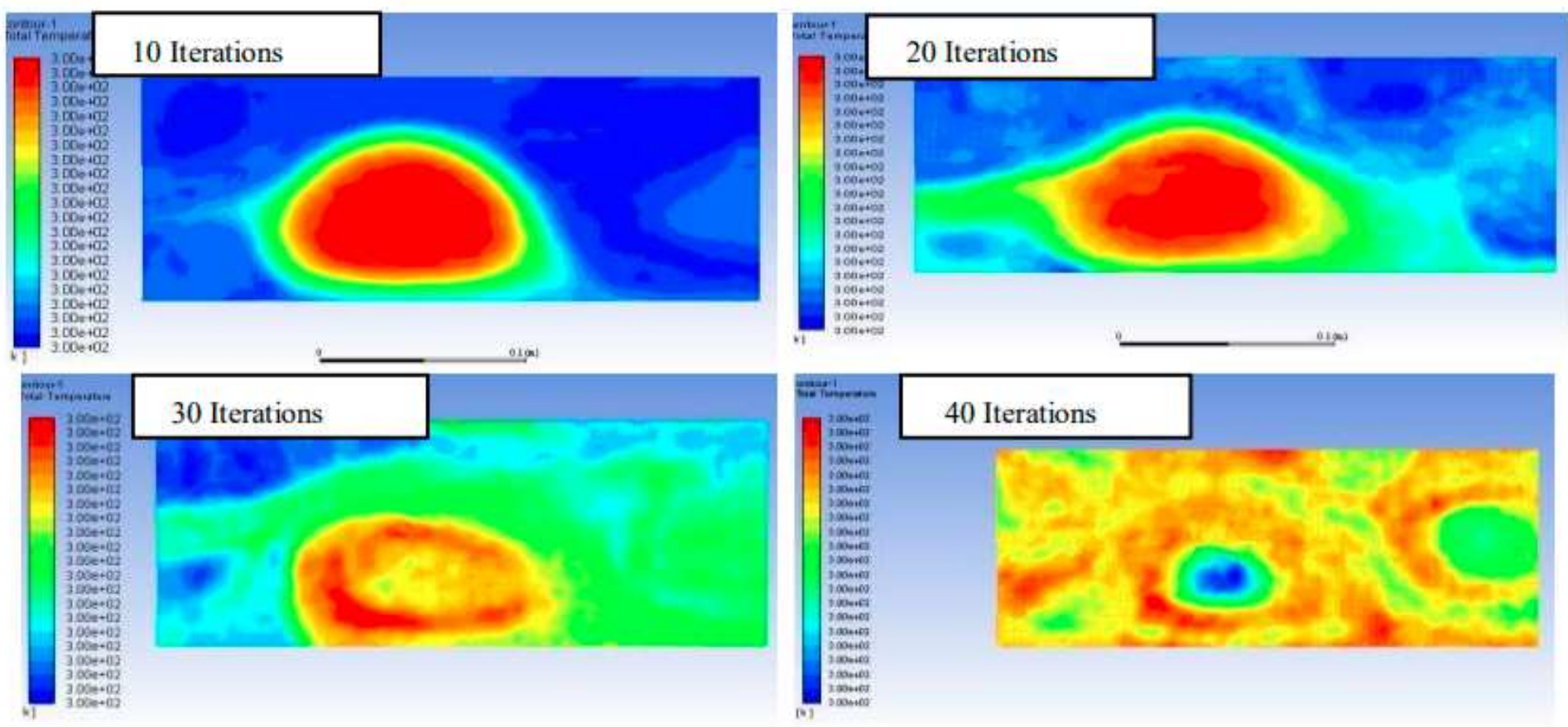

Figure 9

Temperature distribution of elliptical fin
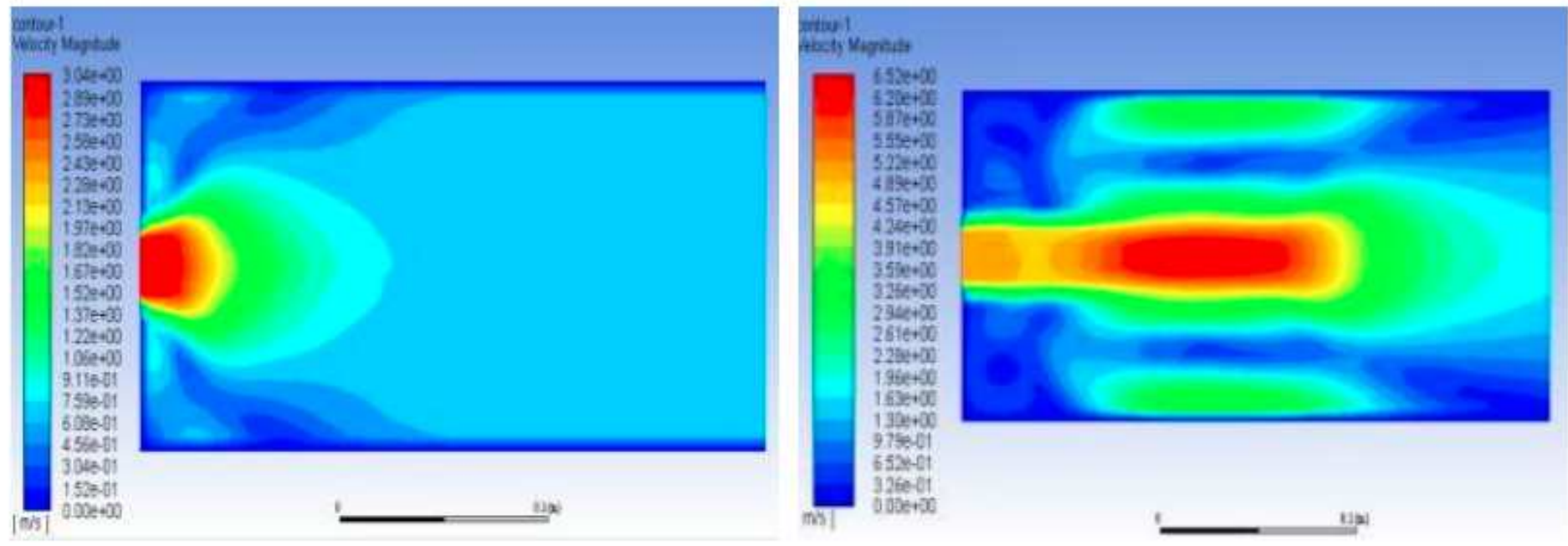

Figure 10

Velocity distribution of Rectangular fin 

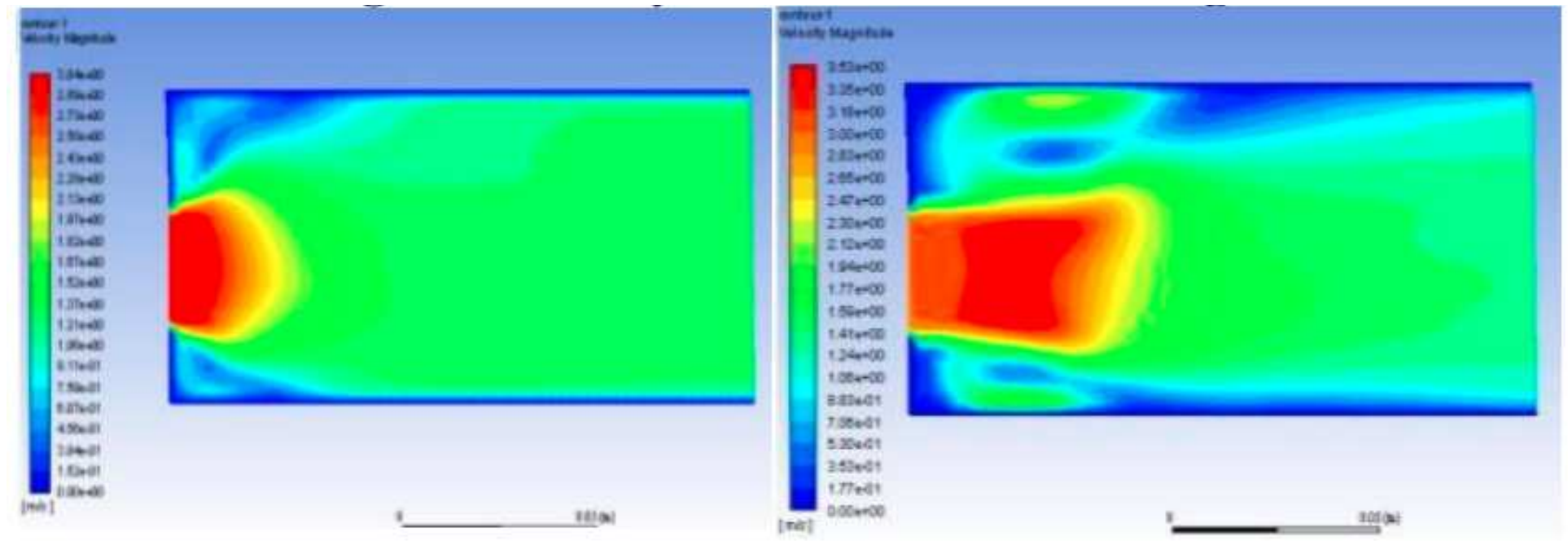

\section{Figure 11}

Velocity distribution of stepped fin
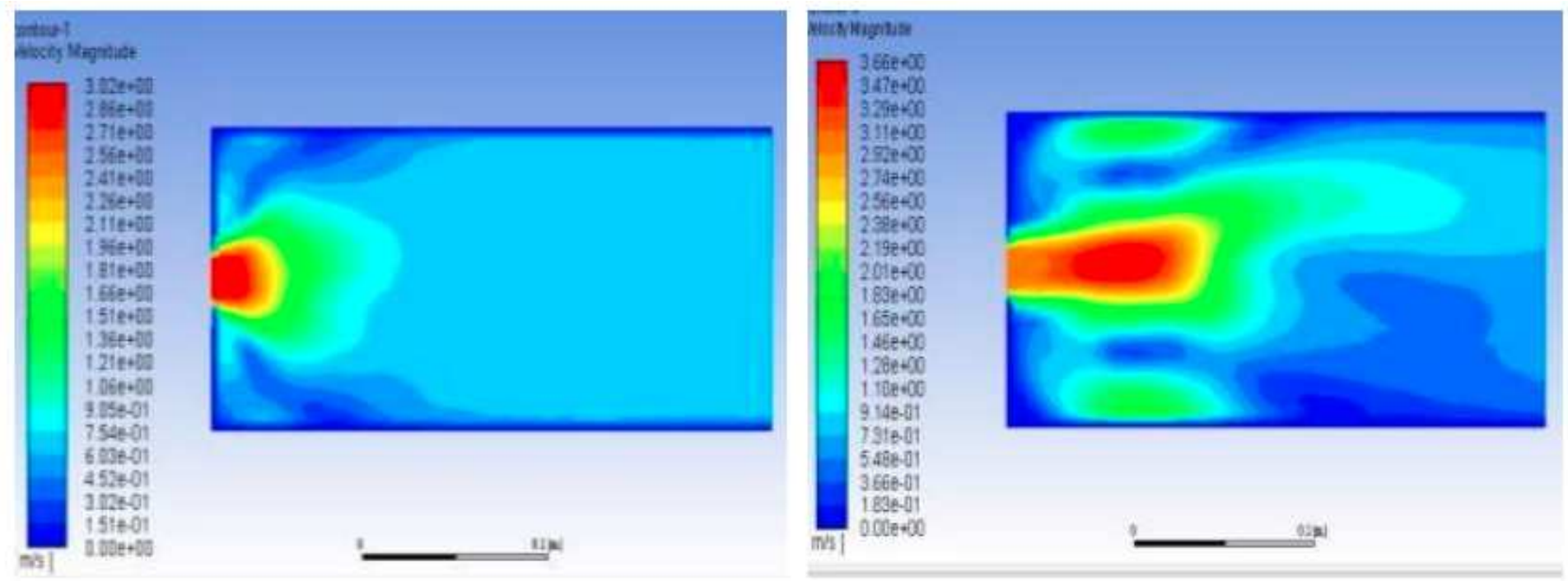

Figure 12

Velocity distribution of elliptical fins 